\title{
Research on the Construction of Teaching Resources against the Background of Internet Plus
}

\author{
Ping ZENG ${ }^{1, a}$ and Xiao-Song ZHOU ${ }^{2, b, *}$ \\ ${ }^{1}$ School of Foreign Languages and International Trade, Wuhan Polytechnic, Wuhan 430074, China \\ ${ }^{2}$ College of Culture and Communication, Wuhan Polytechnic, Wuhan \\ 430074, China

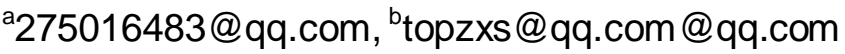 \\ ${ }^{*}$ Corresponding author
}

\begin{abstract}
Keywords: Teaching resources, Curriculum construction, Construction of test question bank, Construction of source material.
\end{abstract}

\begin{abstract}
This paper deals with the construction of teaching resources in the background of Internet plus, including the theoretical value and practical significance of teaching resources construction, as well as the content of teaching resources construction under the Internet plus background.
\end{abstract}

\section{Study on the Construction of Teaching Resources under the Background of Internet the Theoretical Value and Practical Significance}

\section{To Promote the Development of All the Major Information Technology}

The cultivation of teaching resources of all kinds of professionals in information technology is to study how to cultivate information technology talents, how to cultivate information technology talents, what kind of teaching resources to build, and how to build teaching resources. The research process focuses on the wisdom of the best teachers and scientific researchers, and is conducive to the development of information technology. The researches results will make us reexamine and reform the existing curriculum system, curriculum standards, curriculum resources and traditional teaching methods, and will vigorously promote the development of information technology majors. In the era of Internet, information technology is developing rapidly and changing with each passing day. As a major of information technology, it should keep up with the development of technology trend. The construction of teaching resources for the training of information technology professionals is the booster and engine for the rapid development of the information technology.

\section{Make Good Use of Collective Wisdom to Create High Quality Courses}

One of the core tasks of professional construction is the course construction. The construction of high quality curriculum is the core of the construction of teaching resources for professional tal ents. In order to create high-quality courses, each specialty of information technology specialty assigns research expertise and research expertise, and assigns teaching tasks according to each teacher's professional ability and expertise. These research tasks include the study of the teaching methods of different courses, the construction of the curriculum standard, the construction of the question bank, the construction of the platform of the curriculum resources, and so on, and the optimization of the integration of these curriculum resources. The best teachers, the best curriculum standards, the most complete and the most appropriate curriculum resources make the best courses.

Promoting the Sharing of High Quality Resources and Improving the Efficiency of Teachers' Work

Nowadays, the world is the Internet age, the teaching resources of the Internet age must be large and full, and the teaching resources should have the characteristics of sharing. Teaching resources can be shared by different groups of people, including not only different students but also different teachers. High quality and comprehensive sharing of teaching resources and greatly improve the 
efficiency of the work of teachers, teachers from a lot of repetitive, complicated work, can spend more time for other aspects of teaching and scientific research, to improve the quality of teaching, improve teachers' professional level is a virtuous cycle.

\section{Research Contents}

Teaching resources are not a narrow sense of teaching material. Therefore, the research contents of teaching resources construction of information technology professional training mainly include: material library construction, item bank construction, curriculum standard construction and so on. In addition, these resources should be presented in various forms such as online courses on the platform of teaching resources. Therefore, the specific contents of this study include the research of teaching methods, the construction of network courses, the construction of teaching resources platform and so on.

\section{The Construction of Source Material}

Material library construction mainly includes some scientific papers, core codes of program design, website effects, various network textual research materials, and job interview questions. A variety of materials, such as font, text, picture, sound, image and so on. It also includes the most popular, latest related software, and a variety of technical manuals.

\section{Construction of Test Question Bank}

According to the different classification of the course exam, according to some knowledge, the concept of strong content of some of the courses, the use of standardized single topic, multiple-choice questions and judge the questions. Such a question bank needs a certain amount of quantity to ensure that it plays a certain role in the standardized test. The standard question bank is introduced into the online test system or the curriculum resource platform for the purpose of the target test of the course section. The subjective question bank can be used for the final examination of the course on the premise of guaranteeing the number of the question bank. The question bank should be often supplemented and eliminated. The question bank should have certain organizational, detectable, and extensive distribution of content, and it is convenient to maintain.

\section{Curriculum Standard Construction}

First, we must accurately define all kinds of core courses of information technology. Core courses play a key role in information technology professional training programs, and are the core and core of talent training programs. According to the relationship between each core course and the relationship with the goal of talent training, the curriculum standards of each course are determined. The goal of the course is the core of the curriculum standard. The project team will strictly enact the core curriculum standards through the objectives of the course (including knowledge goals, ability goals and quality goals). In the course of setting up the curriculum standard, we should strive to be accurate, specific, scientific and effective.

\section{Research on Teaching Methods}

The main purpose of the construction of teaching resources for the training of information technology professionals is to present these teaching resources to teachers and students in the form of network courses. Based on this, it is necessary to carry out the necessary reform of the traditional classroom teaching methods.

Using case teaching: for some content, case teaching can often through one or more case so that students can learn by analogy, mastery, to achieve a multiplier effect; question driven Teaching: firstly put forward the course to solve the problem, thinking of introducing, then driven by step-by-step approximation thinking and curriculum objectives the problem of the task, and finally to smoothly done or easily solved the problem. In these processes, book knowledge is interspersed and knowledge is integrated into the problem. 
Teaching methods are not static, but flexible according to different courses or even different chapters. Different teachers can also adopt different teaching methods, and students can also choose teachers who are suitable for their "appetite".

\section{Network Curriculum Construction}

The important influence of the development of information technology on the curriculum development of higher vocational colleges is the network problem of the curriculum. That is to say, online curriculum development can publish any courses or trial courses developed by any school and Research Institute quickly, and become the information wealth shared by the society. This greatly broadens the scope of elective courses. Therefore, the development of online courses in higher vocational colleges should pay attention to the selection of elective courses, give students enough freedom to choose courses and independent learning, so as to facilitate students' autonomous learning. Secondly, the development of the network course strengthens the intercourse of the course. INTERACTIVE refers to the interaction between people and computers. People choose their information independently according to their needs, while computers respond to people's choices and provide new information. This process promotes the interaction of teachers and students, students, students and network courses, teachers and network courses, and makes it possible for various courses to be developed. Thirdly, the development of network courses in higher vocational education should be based on the requirements of the technical field and professional post (Group). According to the relevant professional qualifications, the course system based on the work process system and the reform of the teaching content make it meet the goal of high quality and high skilled personnel training. Have extensive and in-depth research and technology industry (Group) occupation qualifications, occupation qualification according to related standards, construction of higher vocational education theory and practice teaching system, curriculum standard and occupation qualification standards, and adjust the content design for the center for professional direction students to cultivate the core ability of occupation. Regularly analyze the changes and new requirements of position and occupation ability, relocate the professional development from the actual industry needs, adjust the curriculum system around professional ability, modify the syllabus in time, and ensure that graduates meet the changing market demand.

\section{Summary}

Practice has proved that in today's rapid development of information technology, building good teaching database is able to improve the efficiency of teachers' work and to play to the collective wisdom construction high quality courses, and beneficial to the development of information technology and curriculum.

\section{Reference}

[1] Xi-bin HANG . To interpret the connotation of the professional teaching resource library of higher vocational college [J]. China electrochemical education, 2010(10).

[2] Hong LUO. The thinking about the construction of Shared professional teaching resource library [J]. Professional education study, 2008(8).

[3] Dong-chuan FANG . The research on the construction strategy of the professional teaching resource library for vocational college sharing [J]. Laboratory research and exploration, 2007(6).

[4] Xiang-yuan MENG. Difficulties and analysis in the construction of digital campus [J]. Science and technology wizard.2012.(17).

[5] Yun-lin LI, Fu-yin XU. The theory and practice of teaching media [M].Beijing: Beijing normal university press, 2003. 
[6] Wen-li LI.To conduct teaching experiment based on thematic learning website in higher vocational colleges [J].Chinese science and technology information, 2005(14). 